\title{
Exploring Management's Perceptions of Succession Planning and its Impact on Staff Retention at an Agricultural Company
}

\author{
Sindisiwe Bonisile Mhlongo ${ }^{1}$, Martha Harunavamwe ${ }^{2}$ \\ ${ }^{1}$ Management College of Southern Africa (MANCOSA), Durban, South Africa \\ ${ }^{2}$ Management College of Southern Africa (MANCOSA), Durban, South Africa
}

\begin{abstract}
Many businesses lack a talent strategy and talent management system component, hence these organisations tend to fulfil their staffing requirements on a reactionary basis but miss a comprehensive career and succession management process. The sugar industry is potentially at high risk for not achieving its goals of increasing production output. This is due to the higher than average age of growers, the nonexistence of effective succession planning to expedite the transition to a new generation of growers, the related increasing departure of farmers from the industry, and lastly the difficulty in attracting new talent to the industry due to the high cost of entry. This research sought to explore employee perceptions of succession planning and the impact it has on retention at an agricultural company. The company recently lost a huge number of employees in managerial and other critical positions due to deaths, retirements, dismissals and resignations. This in turn forced the company to, at times, reinstate retired employees, or hire externally, due to a lack of suitable replacements from the internal workforce. In situations such as this, implementing succession planning could be very useful as it prepares the organisation to fill vacant positions created by unprecedented resignations and retirements. In order to achieve the research aim and objectives, a qualitative approach was utilised in the form of an exploratory case study. A single case study was also chosen because this is a critical, unique and revelatory case. The study found that employees at various management levels within the company understand what succession planning is. However, they perceive that the company is not doing sufficient to implement succession planning programmes. It was also found that there are factors that hinder the successful implementation of succession planning practices at the company. These include poor or absent communication and lack of proper guidance by top management.
\end{abstract}

Keywords: succession planning, talent strategy, talent management

\section{INTRODUCTION}

In today's world, most organisations' staff turnover is on the increase due to unstable and highly competitive business environments (Eshiteti, Okaka, Maragia, Odera and Akerele, 2013:157). Mehrabani and Mohamad (2011:37) state that some factors that cause instability in an organisation's workforce include illnesses, retirements, attritions, or finding better jobs. Garg and Van Weele (2012:96) assert that the lack of proper succession planning in an organisation can have a direct effect of causing business to collapse upon departure of key players. Many companies in the manufacturing sector are experiencing a shortage of skilled employees owing to retirements; deaths, talent poaching and changing of jobs (Human Resource Development Council HRDC, 2012:1). The agricultural company, the organisation under study, has not been immune to such unfortunate events. Research shows that many organisations are not ready or well equipped to confront the talent crisis when it occurs as they usually lack official succession planning programmes aimed at creating "a feeder pool" of highly capable staff members who would be able to occupy management positions in the future (Eshiteti et al., 2013:158). This research, therefore, seeks to explore management's perceptions of succession planning and the impact it has on retention at this company.

\section{Research Context: Background}

In 2014 and 2015 respectively, the company has witnessed unprecedented early retirements by employees in the lower, middle and upper levels of management creating vacant positions. Vacant positions are proving to be very difficult to fill due to a lack of experience and skills on the part of junior employees. At the time of study, early retirements and resignations by managers at all levels is high at the company Ltd at the same time resembling low levels of retention within the organisation's workforce. In reality the organisation is facing a double sword of losing experienced managers 
Sindisiwe Bonisile Mhlongo \& Martha Harunavamwe "Exploring Management's Perceptions of Succession Planning and its Impact on Staff Retention at an Agricultural Company"

through early retirement for greener pastures and lack of skilled junior employees to take over the vacant positions created by the retirees. In situations such as this, implementing succession planning could be very useful as it prepares the organisation to fill in vacant positions created by unprecedented resignations and retirements. The company's senior managers concede that, a succession planning programme is in place as per company policies. However, it is not clear whether the current succession planning program is effective or not. The reader should note that policy documents are removed as references for the sake of confidentiality. All that is revealed by the organisation through records and practices is that the organisation has various development programmes that include Internships, Learner-ships and Engineers-In-Training (EIT) platforms. However these do not form part of a long term strategic plan which will benefit the company in the future as these trainees are normally released after the program has been completed. Implementing an effective succession plan within the company will ensure that internally, the company will have a group of well-developed and trained employees from which the company can recruit. Eshiteti et al. (2013:158) assert that a decline in employee turnover is strongly influenced by the implementation of a powerful succession planning programme. The aforementioned authors further state that when organisations have a functional succession plan, they put themselves in a position of being able to achieve employee retention and job satisfaction.

\section{The Research Problem}

Recently the company lost a number of key employees in managerial and other critical positions due to deaths, retirements, dismissals and resignations. This in turn forced the company to, at times, reinstate retired employees, or hire externally due to lack of suitable replacements from internal workforce. The unprecedented early retirement by managers at all levels and failure by the organisation to fill the vacant positions created by early retirement is a cause for concern at this company. Increase in early retirement and difficulty in filling the vacant positions could be avoided if the organisation had effective succession planning programs in place as it equips employees with the necessary skills to fill vacant position while in the overall serving as an employee retention tool (Gulzar and Durrani, 2014:275). The company has some performance planning practices in place but it is not clear whether such succession planning practices are effective or not. Therefore, the purpose of this study is to explore management's perceptions of succession planning and its impact on retention at the agricultural company.

\section{Research Questions}

- What are the perceptions of employees at management level on the current succession planning practices?

- Does succession planning practices influence staff retention rate?

- What are the factors hindering successful implementation of succession planning?

- What succession planning practices would be recommended that would improve staff retention?

\section{Significance of the Study}

The importance of this study is subdivided into two parts. Firstly, the study will be important to the company as it will inform the leaders about the current perceptions on the available succession planning programs and their influence on staff retention. Ultimately, the leaders might choose to use this knowledge to fine-tune their leadership style with regards to succession planning and management practices. Secondly, it will contribute to the existing body of knowledge. Although there has been various research conducted on succession planning minimum research has been done on this type of industry. Moreover, the findings of this research although focussed on one sugar mill company, it might shed some light on succession planning concerns and the impact caused on management staff retention for other sugar manufacturing industries within the country. The results of the study may also prompt further studies that can eventually lead to some improvements to additional research on the important issues that affect succession planning and staff retention within the sugar manufacturing sector. In conclusion, the success of an organisation depends upon its proactive approach to succession planning and the strategies implemented to retain high talented workforce. World class organisations are achieving much more from their succession plan than just a strategy for loss. 
Sindisiwe Bonisile Mhlongo \& Martha Harunavamwe "Exploring Management's Perceptions Succession Planning and its Impact on Staff Retention at an Agricultural Company"

\section{LITERATURE REVIEW}

Succession planning is vital to instil stability in an organisation since a need for succession can confront any business at any time irrespective of their magnitude or size (Durst and Wilhelm, 2012:639). Hall-Ellis (2015:95) affirms that departures of retiring employees and co-workers leaving the company can have significant consequences. A reflection on previous studies relating to succession planning indicates that, as organisational circumstances change through business growth, promotions and resignations of key staff, proactive succession planning will provide a guarantee that the company will have a backup pool of talent ready to fulfil new roles (Mathur, 2011: 58). Mehrabani and Mohamad (2011: 37) suggests that the key to the future success of an organisation is determined by how it assesses and understands the value of the people it has and what resources it will need in the future. The aforementioned authors further state that the one human resource tool which can assist to determine the current and future needs of the organisation is succession planning. Adewale, Abolaji and Kolade (2011:234) views succession planning as a practice that can offer seamless leadership transition throughout the company. Garg and Weele (2012:97) supports the above authors stating that "succession planning is a deliberate and systematic effort by an organisation to ensure leadership continuity in key positions, retention and development of intellectual and knowledge capital for the future, and encouragement of individual advancement". Adewale et al., (2011: 234) further mentions that it is a strategic, logical and thoughtful effort to improve capabilities of future leaders through planned learning experiences such as targeted rotation and educational training so that top level positions can be occupied without favouritism. According to Garg and Weele, (2012:97), succession planning is actually a practice that warrants uninterrupted effective functioning of an organisation by instituting a process that assists in developing and replacing key staff members over time. Mathur (2011: 50) is in agreement with these writers stating that succession planning system is intended to ensure that skilled and talented employees are made ready to take over each key role in the event of sudden loss of efficiency created by retirements, death, serious illnesses or promotions. The aforementioned author further explains succession planning as some form of internal recruitment where highly capable employees have their abilities, skills and knowledge developed to prepare them to fill-in more challenging and exciting roles. In terms of Stadler (2011:264), succession planning is regarded as "an encompassing term pertaining to a systematic determination of key roles within the organisation, selecting possible replacements, and equipping them with the necessary skills and expertise for existing and future roles". Neo, Hollenbeck, Gerhart and Wright (2012:429) supports the above author asserting that when succession planning practice is put in place, it can identify and develop suitable high potential employees to fill in key positions as they become available within the organisation. Adewale et al. (2011:235) sums up succession planning referring it as a practice of "perpetuating the enterprise by filling the pipeline with highperforming people to assure that every leadership level has abundance of these performers to draw from, both now and in the future". The description of succession planning appropriate for this particular study is by Mehrabani and Mohamad (2011:38) since these authors stress out succession planning as an effort to have a plan for the right quantity and quality of key staff and managers for the anticipated retirements, promotions, serious illnesses, death or any positions, which may be created in the future of the organisation's plans. This particular definition was chosen as it aligns well with the theoretical framework and it also encompasses the relevant dynamics associated with the company's lack of appropriate succession planning practices vital for organisation's resources for maintenance and development.

\section{Staff Retention}

"Turnover is very costly to the organisation in terms of financial bearings, its implications on employee morale and customer satisfaction" (Eshiteti et al., 2013: 159). Tunje (2014: 4) refers to staff retention as the capability of a company to keep its employees from leaving the company while reducing staff turnover. Schroeder, Goldstein, and Rungtusanatham (2013:104) state that employee retention and low employee turnover assist in driving production efficiency and customer value. According to the Business Dictionary, staff retention is defined as a concentrated effort by an organisation to maintain its staff members through the provision of a working environment that supports existing staff members to remain with the organisation. Chitsaz-Isfahani and Boustani (2014:118) on the other hand state that "employee retention is commonly considered to mean the ability to maintain a stable human resource". The above mentioned authors further refer to employee retention as all that energy exerted by the organisation to alleviate the chances of an individual to 
Sindisiwe Bonisile Mhlongo \& Martha Harunavamwe "Exploring Management's Perceptions of Succession Planning and its Impact on Staff Retention at an Agricultural Company"

remain longer within the company. In the words of Das and Baruah (2013:8), staff retention refers to a practice where employees are encouraged to stay longer within the company. Waruiru and Kagiri (2015:3148) assert that the retention strategy has to comprise workforce from different levels since departure of a skilled employee can affect the business at any level, which can lead to escalation of replacement costs within the organisation. According to Chitsaz-Isfahani and Boustani (2014:118), employee retention is the greatest challenge confronted by Human Resource in the modern economy. The writer proposed some effective retention strategies and procedures such as employer branding, changing hiring practices, talent management, and exit interview. The definition that aligns well with the theory or models that will be used in the current study is that of Tunje (2014:4), the author accentuates staff retention as the company's ability to maintain its key workforce, preventing them from exiting the organisation while decreasing staff turnover.

\section{Succession Planning Practices}

Mathur (2011:51) concedes that finding suitable replacements is a process that requires complex design and strategy. The author further suggests a three phase model of succession planning which companies use to characterise their succession and development practises as follows:

- Phase I - Identify key roles for succession or replacement planning and define the competencies and motivational profile required to undertake those roles.

- Phase II - Assess people against these criteria - with a future orientation.

- Phase III - Identify pools of talent that could potentially fill and perform highly in key roles and develop employees to be ready for advancement into key.

Mehrabani and Mohamad (2013:39), affirm that there are other common practices that can assist in successfully achieving effective succession planning efforts. These include:

- Clarifying the aim and the desired results of the effort.

- Determining the requirements of the current performance.

- Measuring the performance and determining the performance that might be needed in the future.

- Assessing the potential, establishing a way to narrow the gaps, following up and documenting competence.

- Making and maintaining rewards for developing people, evaluating results and leading from the front (Mehrabani and Mohamad, 2013:39).

\section{Main Components of Succession Planning}

Stadler (2011: 264) acclaims that succession planning and management should be in line with the organisation's strategic vision and objectives. Mutunga and Gachunga (2013:289) suggests four main components to Leadership Succession Planning.

- The first component is identifying the potential successor - this is the process of selecting a suitable candidate to take over in the event that a key leadership position becomes vacant. This involves identifying at least one or preferable more than one candidate who should begin the succession process as soon as possible and long before the predecessor decides to step down (Mutunga and Gachunga, 2013:289).

- The second component involves changing management style - The succession process requires an incumbent to be taught how to lead and manage, the predecessor must at times forgo their personal leadership and management style and become the teacher and mentor for the candidate (Mutunga and Gachunga, 2013:289).

- The third component is successor training and development - The success of the potential descendent lies in getting the appropriate leadership development training (Mutunga and Gachunga, 2013:289).

- The fourth and final component is selecting the successor - There are many factors to consider when qualifying an individual to lead and manage, these include knowledge, skills, abilities, motivation, ambition, temperament, formal education and experience (Mutunga and Gachunga, 2013:289). 
Sindisiwe Bonisile Mhlongo \& Martha Harunavamwe "Exploring Management's Perceptions of Succession Planning and its Impact on Staff Retention at an Agricultural Company"

\section{Succession Planning Approaches}

According to Stadler (2011: 265), there are three main approaches that are used by most companies to manage succession. These are short-term planning or emergency replacements, long-term planning or management talent and a combination approach.

Short-term or Emergency Replacements: Stadler (2011:265) asserts that regardless of the fact that short-term replacement is the least favoured method, it is the most common succession planning approach. The aforementioned author further states that short-term replacement planning focuses on an urgent need to replace a sudden and unexpected exit of a critical employee. This type of succession planning approach comes to play mostly when the company expands and identifies a talent gap to fill a management role and internal candidates are not suitable. In such cases, human resources often fill the gaps with external recruits.

Long-term planning or managing talent: According to Stadler (2011: 265), the second approach, long-term planning, looks into the future and emphasise attention on the impending needs and requirements of the organisation. Employees are normally invited to take part in an assessment process in order to identify successors in a more scientific manner. Stadler (2011: 265) suggests that the selection of suitable candidates should be in line with strategic context of the company's future goals. The aforementioned author further mentions the advantages for long-term planning approach:

- There is always backup talent with possible successors for every critical role.

- Required future skills are clearly defined for the success of the organisation.

- Employees remain engaged and motivated due to involvement in their career growth and retention (Stadler, 2011: 265).

In addition, Stadler (2011: 265) further points out the disadvantages of this approach such as, being costly and time consuming as well as the fact that the existing employee pool may not have the essential skills and experience for the key job roles and recruiting externally can lead to resentment.

Combination Approach: A combination approach permits top management to strategies for the long-standing growth of both the company and its workforce and prepare for back-up incumbents to make sure that the knowledge loss or lack of skilled employees is not an obstacle for the organisation (Stadler, 2011:265). The business therefore, must tend to concentrate on promoting talent from internally as well as drawing skills from its workforce. This offers a sense of balance in terms of promoting skilled and proficient descendants based on corporate views, policies and plans as well as benefiting from the diverse perspectives, fresh knowledge and a drive to change from new recruits (Stadler, 2011:265).

\section{Succession Planning Best Practices}

McCarthy (2013:10) asserts that succession planning means more than writing up a list of candidates to occupy vacant positions. The aforementioned author further indicates that this is an unfortunate habit for most companies who end up scrambling searching for replacements; employing overpriced external recruits or prematurely promoting internal candidates who are not yet. McCarthy (2013:10) suggests that if an organisation seeks to successfully implement an effective succession planning, it must follow the below 10 best practices:

- Succession planning must not be an HR driven paperwork exercise but commitment and involvement from the CEO and executive management has to be visible. The CEO must own the entire process and hold regular reviews with the Board, and Board members must contribute to the process through giving necessary feedback, asking relevant questions to ensure accountability of the CEO.

- There should be frequent talent reviews where the Board conducts talent evaluations with the CEO; the CEO must assess talent with the executive team, each executive team member to hold reviews with their teams, and the process must cascade down throughout the organisation. This is to identify wide pool of high players and poor performers are also to be dealt with.

- A practicable number of executive level successors must be determined, who then must identify pools of highly talented employees that can be groomed for top level positions. 
Sindisiwe Bonisile Mhlongo \& Martha Harunavamwe "Exploring Management's Perceptions of Succession Planning and its Impact on Staff Retention at an Agricultural Company"

- A pipeline approach to development must be established to identify and develop talent at all levels of the organisation.

- Executive team must be held accountable as they are responsible to measure key activities and results, and often tie them to executive compensation.

- Business strategy must be aligned to clearly link the importance of doing succession planning and the consequences of not doing it.

- Irrational, political and emotional dynamics of succession planning must be managed appropriately as "letting go" becomes a challenge for most people and such heddles must not be ignored since overcoming these comes with experience and emotional intelligence.

- Potential and performance must be assessed, the organisation must not bet on previous performance as a predictor of future success in a new role. A variety of effective ways with relevant and consistent criteria must be utilised to assess potential.

- Succession planning must not be done in isolation but to be integrated with other human resource practices such as performance management, recruitment, selection, development and rewards.

- Serious commitment to development must be made by allocating time and resources. In order for succession planning efforts to prosper, investing in development is highly essential. Successful companies dedicate extra time developing and grooming candidates (McCarthy, 2013:10).

\section{Current Perceptions of Succession Planning Practices}

Research shows that most organisations are generally not fully prepared to confront the sudden talent crisis (Stadler, 2011:264). A lot of businesses lack a talent strategy and the talent management system component hence these organisations tend to fulfil their staffing requirements on a reactionary basis but miss a comprehensive career and succession management process (Stadler, 2011:264). Blazevic (2013:3) states that the sugar industry is potentially at high risk of not achieving its goals of increasing production output. This is due to higher than average age of growers, nonexistence of effective succession planning to expedite the transition to a new generation of growers, related increasing departure of farmers from the industry and difficulty in attracting new talent to the industry due to the high cost of entry (Blazevic, 2013:3). According to Coward (2015:45), there are differing perspectives as to how middle managers and senior managers tackle succession planning and this depends on their experience and perceptions. Govender (2010:8) explain that in spite of most companies investing towards retaining their staff, they still find themselves in a difficult position of not finding proper replacements to fill in critical positions, this in turn limit their potential for growth. Garg and Weele (2012:98) recommend two methods for achieving a successful succession planning process, namely through identifying candidates internally (developing talent) or acquiring them externally (buying in talent). Kowalewski, Moretti and McGee (2011:100) affirm that both internal and external candidates have positive and negative repercussions when entering new positions. Garg and Weele (2012:99) explain that buying in talent involves organisation getting skills from outside the labour markets. This has its advantages and disadvantages including keeping pace with changing market demands, acquiring of specialised skills that the company lacks and attainment of new ideas and new perspectives etc. Unfortunately, this can be expensive and the talent that the company buys is unproven and can have a negative impact on operational performance as talent (Coward, 2012:78). Nonetheless, the business can decide to grow their internal candidates (developing talent) and this aids development of personnel to the particular needs of the organisation, savings on recruitment costs; improving career mobility and engagement within the current labour force (Garg and Weele, 2012:99). The aforementioned authors suggest that there is no wrong or right way in choosing which route to follow when implementing a succession plan. The decision will essentially be influenced by the availability and the readiness of talent within the organisation. Research done by Coward (2012:79) recommends that when organisations have performed poorly, it is advisable to appoint new leadership externally as a turnaround strategy to infuse new ideas and to improve shareholder confidence. Contrary, to businesses that perform well, the company tend to be inclined to appointing replacements of leadership positions from internal pool. Garg and Weele (2012:99) assert that, the internal employees might know and understand the organisation's inner workings but may not recognize the need for change. Whereas workforce from externally might bring new ideas, but many times these new recruits do not have sufficient knowledge of the business to foster the desired changes (Garg and Weele, 2012:99). 
Sindisiwe Bonisile Mhlongo \& Martha Harunavamwe "Exploring Management's Perceptions of Succession Planning and its Impact on Staff Retention at an Agricultural Company"

\section{Challenges Facing the Company under Research}

The company is a medium-size organisation established in 1924, about 90 years ago. The company has five operations located in the KwaZulu-Natal region, and they are namely, Harden Height Farm, Winterhaven Farm, Karkloof Forest, Küsel Sawmill and the their Manufacturing Division. The focus of this study was the Manufacturing Division which has a 24 hour manufacturing facility that produces Brown Sugar products and Wattle Bark Extract products for leather tanning. Like many other firms in the sugar manufacturing sector, this company is experiencing a shortage of skilled employees due to ageing workforce, deaths, and changing of jobs, and this has had a detrimental effect on the performance of the organisation. Eshiteti et al. (2013:159) state that organisations ideally focus on improving their efficiencies; therefore, allowing a high staff turnover of their critical talent is not ideal. The sudden loss of skills in a number of key positions within the company calls for a serious consideration and a need to implement effective succession planning programs to assist in grooming and retaining the talent of the current workforce. Failure to groom young talent to fill in positions on departure of a key player has had damaging consequences for the company. Garg and Weele (2012:96) point out that the absence of a proper succession plan can have direct implications of causing downfall of an enterprise mostly when key and skilful employees exit the system upon retirement or seeking greener pastures. For the company succession planning means predicting an unforeseen circumstance of losing a key skill and taking steps to future proof the organisation by developing a pool of potential successors that can take over should a manager or an employee in a key position leaves. It means planning ahead to attract the best talent, developing and investing in the existing human capital as well as creating a pool of capable workforce in order to retain the skills needed for the success of the organisation.

\section{Benefits of Succession Planning}

Neo et al. (2012: 429) agree to the understanding that succession planning is all about finding and preparing potential successors to occupy critical positions within an organisation. Mehrabani and Mohamad (2011: 38) assert that the key goal of succession planning is to "develop people to increase their managerial power". Kowalewski et al. (2011:99) support this view by stating that, historically, succession planning focused on developing employees to fill higher level management positions. Presently, companies are using this planning for all levels of their organisation (Kowalewski et al., 2011: 99). The abovementioned authors further stressed out the importance of constantly reviewing and updating the tools that are well-known to track, mentor, and train upcoming leaders for a company as employees retire, find opportunities elsewhere, are promoted from within, are terminated, leave the workforce. According to Kowalewski et al. (2011:100), succession planning has a great influence in making an organisation to succeed and to become more competitive. It also improves the retention of gifted employees and reduces the possibilities of losing critical skills and knowledge when employees leave the company. Kowalewski et al. (2011:100), questions as to why more organisations are not implementing succession planning if it has so many benefits. The abovementioned author further points out one of the benefits of succession planning as the major contributor to staff retention that results to increased staff performance. Moreover, future planning is understood to reduce recruitment costs because recruiting can be accomplished in periods of lowered stress, hiring the best talent, not just a body to fill a seat (Kowalewski et al., 2011: 100).

\section{Key Steps to Achieve Successful Succession Planning}

Research done by General Electric Capital Corporation (GECC) suggested that in order to assess key positions, the top management must take stock of the key positions that are required to fulfil organisational objectives and assess the abilities, skills and experiences needed for each important role. Leadership positions assessed for both their business impact and the risk of retaining the incumbent, focusing the bulk of its succession planning on the high-risk, high-impact roles. Important to this assessment is conceptualizing the significant features needed from the candidate to fulfil the roles. Kowalewski et al. (2011:100) asserts that there are various ways of categorizing and ranking the importance of positions within the company. Kowalewski et al. (2011:100) suggest that the first thing to do is to evaluate and decide as to which positions are critical roles within the organisation and once these positions have been identified, they can be separated into four categories and specific action must be taken for each role type:

Strategic: These roles require employees with specific skills and knowledge as the functions are critical in driving long-standing success and competitive advantage for the organisation. The action to 
Sindisiwe Bonisile Mhlongo \& Martha Harunavamwe "Exploring Management's Perceptions of Succession Planning and its Impact on Staff Retention at an Agricultural Company"

put in place is to create a backup pool in these roles by employing new staff or implementing targeted development.

Core: These roles are the engine of the organisation which are unique and are core in delivering its products and services. The action to undertake for these roles is to always protect them so that the organisation constantly has capabilities to fill any gaps through aggressive in-house development.

Requisite: Even though the company cannot function properly without these roles, their value could be carried out through unconventional staffing approaches. Action to implement is to streamline or subcontract these roles.

Non-core: People in these roles have a set of skills that are no longer linked with the business's strategic direction. Action to take is to shed these roles.

Mathur (2011:52) advocates that there is no widely accepted way of assessing the future prospective leaders; however, the evaluating process is a vital practice in effective succession planning. The above mentioned author further stipulates that there are plenty tools and approaches that are used in nowadays, ranging from personality and cognitive testing to team-based interviewing and simulations and other assessment centre methods.

\section{Factors Hindering Succession Planning}

Mutunga and Gachunga (2013:288) view succession planning as a unique process where one-size-fitsall approach is simply not appropriate. Research maintains that there two conditions which are important for the succession planning to be successful, firstly, it is the eagerness of the descendant to show a long-lasting commitment to the organisation and secondly, it is the successor's responsible "to acquire the required knowledge, skills and competencies necessary to manage within the finite timespan leading up to the retirement of the incumbent". (Mutunga and Gachunga, 2013: 288). Mathur (2011: 55) maintains that there are several factors which affect the process of succession planning. These factors do not only affect the productivity, reputation, brand image and morale of employees but affect the overall organisation. These factors include succession plan, size of company and leadership development. These are discussed as follows:

Succession Plan: It offers a blueprint for the growth of the organisation and is vital to the prolonged existence of any business. Executing a succession strategy can be daunting as it is not a one-size-fitsall but needs to be customized for each particular organisation. It should be considered that what works well for one company might not work for the other (Mathur, 2011:55). The important factors that assist to guide organisation in undertaking succession planning include having a strong HR that will take succession planning practices very seriously (Mathur, 2011:55). Succession planning as part of Recruitment Plan, Training Plan and Career Growth Management Plan with Performance Appraisal and HRMS tools, assists to ensure that the right kind of people in right numbers at the right time is available to help in sustaining continuity of strength and vitality of an organisation (Mathur, 2011:55).

Size of Company: According to Mathur (2011:55), a large size company must ensure that it has a larger pool of potential successors to choose from. The organisation may in the beginning identify several candidates followed by monitoring their performance and later make a decision when it is closer to time for them to take over. With smaller organisations, however, designating a replacement may be more challenging. The organisation might have a shortage of employees prepared to take over, and there may be a need to employ someone precisely for the position, or hire employees based not only on how qualified they are for the job, but on how qualified they are to move up to higher-level positions (Mathur, 2011: 55).

Leadership Development: Successful succession planning does not only depend on identifying suitable candidates to take over, but mentoring potential successors to ensure they are well equipped (Mathur, 2011:55). The biggest mistake that most companies do, is simply replacing key executives instead of assessing all employees and identifying and training any person with potential to move up (Mathur, 2011:55). Organisations with leadership development programmes in place normally will have a much larger feeder of successors from which to choose from, and who will be better trained to take on a greater variety of roles.

\section{Internal Factors}

According to Mehrabani and Mohamad (2011:38), there are many obstacles that could interrupt the process of succession planning. These impediments and difficulties may differ and dependent on organisational culture, strategy, and economic circumstances. The aforementioned authors state that 
Sindisiwe Bonisile Mhlongo \& Martha Harunavamwe "Exploring Management's Perceptions of Succession Planning and its Impact on Staff Retention at an Agricultural Company"

many organisations do not dedicate time to succession planning as a few understands the value of it. Many organisations are preoccupied with current issues in their business and do not contemplate about the future (Mehrabani and Mohamad, 2011:38). Understanding the significance of succession planning to categorise, handpick, and develop the upcoming leader would be an additional obstacle when they are not fully prepared to fill in the shoes as the successor. According to Mehrabani and Mohamad (2011:39), it is difficult at times to think succession of the existing manager who has occupied the current position for a long time as some would like to keep their jobs forever and never leave. The aforementioned writers assert that some leaders and managers tend to desperately want to keep their position that they concentrate only on their own needs instead of the organisations. It is therefore important to be acquainted with the obstacles which may occur when implementing a strategic succession process as this will provide a foundation for realizing key issues concerning of resources in order to identify the training needs to implement the strategic plan for the employees (Mehrabani and Mohamad, 2011:39).

\section{External Factors}

Attrition remains a key organisational burden in this globalised economic environment and maintaining best talent is crucial in acquiring a competitive advantage for any organisation (Koranteng, 2014:33). Terera and Ngirande (2014:483) assert that, financial rewards play a substantial role in employee retention. This view is reinforced by Selesho and Naile (2014:298) who state that unappealing remuneration packages add to staff migration in most industries. "Compensation is a major factor employees consider when making the decision to leave or remain in an organisation" (Terera and Ngilande, 2014:487). "Over and above financial related issues, respondents cited job satisfaction, lack of growth within the company, location and accommodation issues as some of the factors that affect staff retention within the company.

\section{Staff Retention Theories}

According to George (2015:103), there are quite a number of factors that have great influence on staff retention. These include "the culture of an organisation, developmental opportunities, the quality of supervision, job stress, colleague stress, compensation and appreciation of performed work, provision of challenging work, promotion and development chances, inviting atmosphere within the organisation, positive relationships with colleagues, a good balance between professional and personal life, good communications and supervisor support" (George 2015:103). Chitsaz-Isfahani and Boustani (2014:118) argue that the top five key factors that can influence staff retention within the organisation include:

- exciting work / challenge;

- career growth / learning;

- relationships / working with great staffs and employees;

- fair pay;

- supportive management / great manager or supervisor

George (2015:103) concluded that, employees are more likely to stay longer in a company that has appropriate management style, where the working experience is pleasurable, resources are sufficient, and there is a degree of flexibility where there are ample opportunities for growth, teamwork is encourage and a friendly environment promoted. The above mentioned author further asserts that "employees stay longer in jobs where there is some degree of autonomy, where there is flexibility in workload decisions, where pay decisions are transparent and fair, where there is some opportunity for individuals to craft their jobs and where there is a suitable work-life balance"(George , 2015:103).

\section{Conclusion}

It can be concluded that predicting the future success can reveal undiscovered abilities and talents in the workforce. An effective succession planning and management emphasis must therefore reflect employee's development needs for all job categories (Mehrabani and Mohamad, 2011:38). The abovementioned author's further mention that the single most crucial goal of succession planning program is to preserve talent by ensuring that employees are kept motivated and engaged. This allows talented employees to move their tracks faster and more appropriate (Mehrabani and Mohamad, 2011: 
Sindisiwe Bonisile Mhlongo \& Martha Harunavamwe "Exploring Management's Perceptions of Succession Planning and its Impact on Staff Retention at an Agricultural Company"

38). Garg and Weele (2012:99) suggest that providing coaching, mentoring or additional job training to existing employees will result to huge savings. Businesses who fail to preserve their talent are on the risk of losing out to competitors. "Through an effective succession planning practice, organisations are able to chart out employees retention strategies through recruitment and selection, training and development and effective compensation system" (Koranteng, 2014:33).

\section{RESEARCH METHODOLOGY}

Zikmund, Babin, Carr and Griffin (2013:5) define research method as a "strategy of enquiry". According to Barbour (2014:18), research methodology means the philosophy of the research process. This refers to the approach that underpins the research (Flick, 2014:112). The author continues to reveal that the approach includes the assumptions and values that serve as the rationale for research and the standards or criteria the researcher uses for interpreting data and reaching conclusions.

\section{Research Design}

According to Collis and Hussey (2003:113), "research design is the science and art of planning procedures for conducting studies so as to get the most valid findings. Determining your research design will give you a detailed plan which you will use to guide and focus your research". The empirical study can be quantitative or qualitative in nature or consist of both. Quantitative research is defined as a form of research that solves problems "through empirical assessments that involve numerical measurement and analysis approaches" (Zikmund et al., 2013:134). Qualitative research methods have been described as "an array of interpretative techniques" aimed at describing, decoding, translating and otherwise coming to terms with the meaning, not frequency, of certain more or less naturally occurring phenomena in the social world (Creswell, 2015:30). Qualitative case study research method has been adopted in this study. The nature of this research, requires that the qualitative explorative research design approach be used. Baxter and Jack (2008:544) state that "qualitative case study methodology provides tools for researchers to study complex phenomena within their contexts". According to Burritt and Saka (2006: 1266), a case study can provide rich descriptions, explorations and explanations of the phenomena being studied, and are of particular use where little prior study has been undertaken. Yin (2012:9) states that a case study design should be considered when: a) the focus of the study is to answer how and why questions; b) you cannot manipulate the behaviour of those involved in the study; c) you want to cover contextual conditions because you believe they are relevant to the phenomenon under study; or d) the boundaries are not clear between the phenomenon and context. Therefore, in this study, the case study is used because of the complex phenomena surrounding the company, particularly given that the succession planning issues are not clearly understood. The case of how succession planning is applied by the company is still in question. Therefore, perceptions of employees at management level on the current succession planning practices cannot be noticed and decisions cannot be recommended without conducting research in this regard.

\section{Determining the Type of Case Study}

In this study, the type of the case study that is used is exploratory case. This type of case study is used to explore those situations in which the intervention being evaluated has no clear, single set of outcomes (Yin, 2012:47). Since the issues surrounding succession planning practices within the investigated company are still new, it is not clear how they are applied. The use of case study as a research approach to collect data is appropriate for this study because it is a means to provide rich drawings, descriptions, considerations and clarifications of the events being investigated. Saunders, Lewis, and Thornhill (2012:179) write that the case study strategy has also considerable ability to generate answers to the question 'why?' as well as 'what? and 'how?' questions. The case study strategy is, therefore, appropriate because this research has posed questions that this study seeks to answer. A single case study was also chosen because this is a critical, unique and revelatory case and the researcher had access to the case previously inaccessible to empirical research. Yin (2012: 48) also supports this rationale for a single case study. Another rationale for choosing a single case study is that this is the representative or typical case, as Yin (2012:48) puts it. A representative or typical case is the one that provides insight into a broader phenomenon that is common within the same industry (Yin, 2012: 48).

\section{Data Collection}

The main method of data collection in this case study was in-depth interviews. Yin (2012: 114) suggests three main sources of data collection for qualitative research methods and these are in-depth, 
Sindisiwe Bonisile Mhlongo \& Martha Harunavamwe "Exploring Management's Perceptions of Succession Planning and its Impact on Staff Retention at an Agricultural Company"

open-ended interviews, direct observation and written documents. Flick (2014:208) points out that indepth interviews allow deep information and knowledge to be sought, with this information usually being related to personal matters, such as values and decisions, cultural knowledge or perspective. Indepth interviews minimise the chances to report on researchers' own perceptions; whereas direct observations and documentary evidence would require researchers to place far more of their perceptions into the interpretation of data sources. Chang (2007:110) suggests that in-depth interviews be used in conjunction with data gathered through such avenues as informal interviewing and documentary records. Therefore, the primary data collection for this study came in the form of indepth interviews using semi-structured questions. Furthermore, additional documents were analysed. These included the company's succession planning policy, employment equity policy, corporate governance guidelines, and company commitments guidelines.

\section{Target Population}

The population is the pool from which the sample elements are drawn, and to which the research wishes to generalize findings from (Saunders et al., 2012: 167). Population refers to the entire group of people, events, or things of interest that the researcher wishes to investigate (Sekaran and Bougie, 2013:267). According to Sekaran and Bougie (2013: 267), "the target population must be defined in terms of elements, geographical boundaries and time. An element is a single member or unit of the population". Mutunga and Gachunga (2013:290) add that population of the study can be defined as an inclusion of all individuals or items with the characteristics that are to be understood. Therefore, the target population consisted of all employees employed at the management level at the company.

\section{Sampling and Sampling Method}

Sampling is the process of selecting a sufficient number of the right elements from the population, so that a study of the sample makes it possible for one to generalize to the population elements, including those not selected in the sample (Sekaran and Bougie 2013:245). Saunders et al. (2012:261) indicate that it is of paramount importance for the sample to best represent the characteristics of the population. According to Zikmund et al. (2013:166) the following are characteristics of a good sample design:

- It must result in a truly representative sample.

- It should minimize sampling error.

- It must minimize systematic bias.

- The results from the sample should be applied to the population from which it was drawn with a reasonable level of confidence.

There are two main types of sampling design namely probability or nonprobability sampling. Probability (random) sampling is the most attractive and considered the best technique of selecting a representative sample as it ensures that every element has an equal chance of inclusion in the sample (Saunders et al., 2012:262). The aforementioned authors assert that one of the most used sampling methods is probability sampling which may be classified as simple random sampling where each element of the population has an equal (unrestricted) chance of being included in the sample. The participants in this study were managers, supervisors, assistant supervisors and foremen because of their vast knowledge and experience that was considered valuable for this study, hence judgemental. This consisted of Human Resources Manager, Research and Development Manager, Production Manager, Training Manager, Sales Manager, Plant Engineer, Project Engineer, Safety, Health and Environmental (SHE) Officer, Stores Controller, Extract Factory Foreman, SPP supervisor, Assistant Production Manager - Extract, Assistant Production Manager - Sugar, Technical Assistant: Quality Control, and Management Accountant. A total of 15 individuals participated in this study. According to Saunders et al. (2012:283), this sample size is sufficient and appropriate. Creswell (2015: 77) recommends a sample size of between 3 to 10 participants for phenomenology studies like this one, where a qualitative evaluation is performed. The interviews were conducted between May and June 2016 based on the availability of the informants using an audio recorder.

\section{Interview Design}

The literature review guided the formulation of interview questions. The interview questions were structured such that they address the research objectives and questions for this study and were categorised into the following themes: 
Sindisiwe Bonisile Mhlongo \& Martha Harunavamwe "Exploring Management's Perceptions of Succession Planning and its Impact on Staff Retention at an Agricultural Company"

Theme1: Perceptions on the available succession planning programmes

Theme2: Factors that influence the successful implementation of succession planning.

Theme 3: Challenges pertaining to staff retention. Face-to-face interviews were conducted with 15 individuals who participated in this study. The interviews were conducted between May and June 2016 based on the availability of the informants using an audio recorder

\section{Data Analysis}

The recorded interviews were transcribed, that is, produced as a written account in words. The transcribed data was then compared with field notes to ensure data accuracy. Thematic coding was used to categorise findings from the case being investigated. Thematic grouping of text paragraphs rather than a scoring process minimises potential for bias (Chang, 2007:116; Sekaran and Bougie, 2013:339). Data was analysed via a within-case approach using complementary word tables. According to Yin (2009: 160), the analysis of the entire collection of word tables enables the study to draw within-case conclusions and probe whether different individuals appear to share some similarities and deserve to be considered instances of the same type of general case.

\section{Reliability and Trustworthiness, Bias and Validity}

In qualitative research, reliability is concerned with whether the findings from the case study can be replicated if the case study is done by alternate researchers (Saunders et al., 2012:381). Flick (2014:481) asserts that if a research finding can be repeated, it is reliable. The same interview questions were asked to all the participants as this technique enhances the reliability of data being collected and the informants reviewed the transcripts for accuracy (Lapan, Quartaroli and Riemer, 2012:183). Reliability was also increased by using multiple sources of data. Therefore, apart from collecting data through semi-structured interviews, data was also collected from the analysis of company documents Tracy (2013:41) writes that an underlying principle in the collection of data in case research is that of triangulation, i.e., the use and combination of different methods to study the same phenomenon and it is considered worthwhile because a key concern for good research is its reliability and formal generalisability. Triangulation is a practice in which a researcher uses multiple types and sources of data, variant methods of collection, as well as theoretical frames and multiple researchers (Tracy, 2013: 63). According to Lapan et al. (2012: 251), triangulation increases validity and trustworthiness of findings. Hence, this study used triangulation to enhance the reliability and trustworthiness of data.

Bias

It is said that case study researches are prone to preconceived notions that might motivate them to conduct the case study and this makes the study to be biased (Sekaran and Bougie, 2013: 150; Yin 2009: 72). To address the concern for bias in case study research, Yin (2009: 72) suggests that the researcher needs to be open to contrary findings. To reduce any likelihood of bias, this study adopted what has been a norm in many case study researches. Where any preconceived views, assumptions, and concepts were wrong, the researchers had to revise their hypotheses to align them to new findings. The researcher was tolerant to contrary findings. Bias was addressed mostly through data triangulation. Flick (2014: 187) maintains that triangulation enables the researcher to overcome the potential of bias of a single-method approach. Data was collected at different times, from different sources. Yin (2009:72) also suggests that the researcher reports his or her preliminary findings, possibly while still in the data collection phase, to two or three critical colleagues. The colleagues should offer alternative explanations and suggestions for data collection. If the quest for contrary findings can produce documentable contradictions, the likelihood of bias will have been reduced. Therefore, to address bias, the researcher also reported preliminary findings to two human resources management academics to provide their critical evaluation. Their suggestions and inputs were incorporated to this study and this ensured that bias was minimised.

\section{Validity}

Zikmund et al. (2013:303) define validity as the accuracy of a measure or the extent to which the research findings accurately represent what is really happening in the situation. Research errors, inaccurate or misleading measurement can undermine validity (Flick, 2014: 483). Yin (2009:40) write that case study research should fulfil the same requirements as any other methodology in social sciences for being considered as a rigorous research method. To address validity, the study ascertained the fulfilment of these requirements: 
Sindisiwe Bonisile Mhlongo \& Martha Harunavamwe "Exploring Management's Perceptions of Succession Planning and its Impact on Staff Retention at an Agricultural Company"

Construct Validity: Construct validity is a measure of whether consistent operational measures for the concepts being studied are established (Chang 2007:118). This study used related information collected from available sources such as company website and policies. The researcher read transcripts repeatedly to ensure accuracy and three managers who participated in this study also reviewed these transcripts.

Internal Validity: Since this research used a single case study approach with embedded units, data was analysed for each unit and then analysed across units to discover a pattern across units. This seeks to establish a causal relationship, whereby certain conditions are believed to lead to other conditions (Masanet-Llodr, 2006:396).

External Validity: External validity is related to generalisation which, in turn, is concerned with the application of research results to cases beyond the one studied (Zikmund et al., 2013: 304). This study endeavoured to maintain a chain of evidence which Yin (2009:122) recommends as a principle to be followed in order to increase reliability of the information. The principle is to allow the external observer, i.e., the reader of the case study, to follow the derivation of any evidence from initial research questions to ultimate case study conclusions.

\section{Ethical Considerations}

Barbour (2014: 79) states that to be ethical is to conform to acceptable professional practices. Ethics are norms and standards of behaviour that guide moral choices about our behaviour and our relationship with others (Sekaran and Bougie, 2013: 13). The following is a summary of some ethical principles that were upheld when conducting this study:

Honesty: The researcher needed to strive for honesty in all scientific communications and honestly report data, results, methods and procedures, and publication status. Hence, there is no fabricating, falsifying, or misrepresenting data.

Objectivity: The researcher had to strive to avoid bias in empirical design, data analysis, data interpretation, peer review, personnel decisions, expert testimony, and other aspects of research where objectivity is expected or required. The investigator endeavoured to avoid or minimize bias or selfdeception and avoid disclosing personal or financial interests that may affect research.

Integrity: The researcher kept to promises and agreements; acted with sincerity; strived for consistency of thought and action, tools, resources and was open to criticism and new ideas.

Confidentiality and Anonymity: Participants were assured that all information obtained would be used for research purposes only and participants would not be identified by their names in any report of the completed study. Therefore, data was collected anonymously and names were not to be linked with any information.

\section{RESULTS}

The majority of the respondents were males $(73 \%)$ as compared to the female representation at $27 \%$. The racial grouping of the respondents indicates that $33 \%$ were African, $47 \%$ Indian, and $20 \%$ White. Coloureds were not represented in this study. The demographic profile of the participants shows no participation of managers below 20 years up to 29 years. The majority of participants were between the ages of $30-39$ years at $47 \%$ and $40-49$ years at $40 \%$. Also an age group of $50-59$ years at $13 \%$ participated in this study, whilst nobody at 60 years and over formed part of the respondents. The largest number of respondents were those who possessed between $1-5$ years of experience $(66 \%)$. The balance of respondents possessed experience of $5-10$ years (13\%), $0-1$ year (7\%), $10-15$ years (7\%), and 15 years and more (7\%). The majority of management staff at UCL Company (Pty) Ltd, who participated in this study, holds an undergraduate degree $(40 \%)$. The least qualified were those who did not have matric (7\%). 13\% represents those who held an Honours/B.Tech degree. The balance represents those who have matric (20\%), Certificate (7\%), Diploma (7\%), and a PhD (7\%). No member of management holding a Master's degree participated in this study. The demographic profile reveals that the company is dominated by males who occupy management positions $(73 \%)$. The experience of the majority of the respondents $(66 \%)$ suggests that managers do not stay long in those positions or within the company. There was uniformity in informants' responses as to what succession planning is all about. Respondents share a common understanding that succession planning entails developing employees internally for senior positions to ensure continuity. There is no 
Sindisiwe Bonisile Mhlongo \& Martha Harunavamwe "Exploring Management's Perceptions of Succession Planning and its Impact on Staff Retention at an Agricultural Company"

consensus agreement in terms of managers' responses regarding the availability of candidates internally to succeed the current managers. The company's management accountant concedes that within her department there are good potential candidates to succeed the current manager, however, in the production department there is no one groomed to take over from the current manager. The informants' responses were based on their experiences within their respective departments. The majority that agreed that they have internal candidates who can succeed the current managers in their departments, also pointed out that in other departments such as production, engineering and electrical, there are no candidates available. It can therefore be concluded that certain departments with the company, have candidates internally, who can succeed the current managers or who could be placed in key positions. The respondents, who conceded that there were no internal candidates who can succeed the current managers, stated that the company needs to conduct training and development internally in order to ensure that skilled employees are available to succeed the current managers should there be vacancies. Respondents were divided about how the company gets to know internal candidates well enough to promote them into management positions. These differing responses may be due to the fact that some managers are of the view that there is no specific system used to assess internal candidates for promotion into management positions. However, the majority of respondents reveal that the company uses the performance management system to assess internal candidates' competencies. Some respondents stated that foremen, supervisors and managers are used as informants to gather information about internal candidates to know them well enough to promote them into management positions. The HR Manager also added that the company also considers experience and qualifications of internal candidates as part of the information sufficient to know them and consider them for promotion. Respondents are not in agreement about how the company gets to know external candidates well enough to make an informed decision to recruit them for a management position. The general response from informants is that the company applies its recruitment policy which involves using recruitment agencies, conducting shortlisting process and then interviews. According to the HR Manager, the recruitment process includes looking into external candidates' qualifications, experience and doing reference checks. Informants also reveal that the company being investigated uses PPA as a tool to get to know external candidates. The company's management accountant mentioned that the current recruitment policy has some weaknesses, in that background checks are not done on candidates and it is not implemented effectively. The majority of respondents do not see much action being taken at the company, to assess and develop internal candidates. However, some informants mentioned that there are programmes available for employees such as opportunities for staff members to further their studies, management courses for supervisor and foremen and artisan programmes. The general view is that the majority of these programmes are done informally. For example, the SHE officer and the Training Manager are in agreement that there are no formal programmes in place to assess and develop internal candidates within the company.

\section{Conclusions to theme 1 and objective 1}

Under this theme it can be concluded that employees at various management levels within the company understand what succession planning is. However, they perceive that the company is not doing enough to implement succession planning programmes. The general perception is that the company has potential candidates who can be trained and developed into management positions. It also emerged that there are programmes in place aimed at developing and training internal candidates for management positions, however, these programmes are either not formal or not yet implemented.

\section{Theme2: Factors that Influence the Successful Implementation of Succession Planning Practices}

The majority of respondents share the same view that top management ensures that they put in place the process/programmes necessary to create room for future leadership talent mainly by offering training and development programmes or offering study incentive schemes. All respondents are in agreement that there are internal factors affecting the successful implementation of succession planning within the company. These include lack of knowledge and motivation by top management, lack of time and willingness of employees to participate in training and development programmes, lack of succession planning strategy from top management and costs of implementing succession planning programmes. All the respondents think that there is no sufficient awareness among employees with the company regarding the succession planning issues. The Technical Assistant: QC responded to the question by saying that "Even myself I am not really familiar with it". The Extract Factory Foremen stated that "I don't think it is filtered down to the employees". The plant engineer 
Sindisiwe Bonisile Mhlongo \& Martha Harunavamwe "Exploring Management's Perceptions of Succession Planning and its Impact on Staff Retention at an Agricultural Company"

added that "Maybe the top management has the awareness It evident that the company under investigation has, to a certain degree, some programmes in place geared towards advancing the implementation of succession planning, even though they appear to be informal. It can be concluded under this objective that there are factors that hinder the successful implementation of succession planning practices at the company. These include poor or absent communication with regards to succession planning programmes within the company, lack of proper guidance by top management, lack of time and willingness of employees to participate in training and development programmes, lack of succession planning strategy from top management and financial constraints.

Theme 3: Challenges pertaining staff retention and factors that might influence the employees to remain within the organisation

Objective 3 sought to explore whether succession planning practices influence staff retention at the company. There was uniformity in informants' responses to the question. It is evident that there are challenges with regards to retaining current managers within the company. The mostly cited challenge is remuneration. All respondents agreed that the company is faced with retention challenges pertaining potential managers. According to the respondents, these include inability to identify candidates to be groomed for management positions, limited time to groom potential candidates, lack of job satisfaction, remuneration issues and geographical location. The main challenge cited above was the lack of promotion opportunities with the company. The $\mathrm{R}$ and $\mathrm{D}$ Manager stated that "The most obvious challenge is that in some management positions we have fairly young managers who are expected to stay long, so potential managers would look for opportunities elsewhere". The Production Manager added that "people occupying almost 30 years in one position get demotivated". The majority of informants concede that there are talent gaps within the company while only one respondent believed that there are no talent gaps. The other respondent was not sure about the question. Talent gaps perceived to be lacking at company are mainly technical and soft skills. Basic management skills were also mentioned as a missing element within the company. Respondents assert that talent gaps can be addressed by putting in place training and development programmes, proper communication channels to share information amongst staff members and to recruit qualified people who have relevant qualifications and experience. All respondents agreed that there are challenges outside the company affecting its ability to recruit needed talent. Ten out fifteen participants pointed out that the company's geographical location is the main challenge. This is due to the fact that the company is located in a rural area. According to the participants, the location affects the quality of life and there is no variety of good schools for their children in the village at which the company is situated. The Training Manager revealed that "managers from the city find it difficult to adopt in such an area". She added that "the geographical location is not friendly to young potential managers". Apart from geographically related challenges, it also emerges that, other challenges relate to the scarcity of skills in the country and as such there is competition amongst employers for these skills. Adding to these challenges, are remuneration related challenges. The majority of the informants would be motivated to stay longer in the company if they are part of the succession planning programme. These respondents cited that being part of the succession programme would ensure growth within the company. The Project Engineer, for example, said "as long as it guarantees promotion". When participants were asked as to what else would motivate them to remain in the company, they had differing opinion. Given the current restructuring within the company, some respondents mentioned that job security and certainty would motivate them to stay. The general response is that participants agree that learning and development opportunities will influence and motivate them to stay longer within the company, however some respondents added should opportunities arise, they would leave the company. Those who agreed to the question mentioned that being given learning and development opportunities implies that the company is preparing them for future management positions. One respondent stated that "I must not be told what I must learn. It must depend on what skill I want to learn" suggesting that he would want to be involved in deciding upon which learning and development programme he will have to undertake within the company. A staggering number of respondents do not think that the current succession planning programme will assist in retaining employees. Only two out of fifteen respondents agreed that the current succession programme will assist in retaining employees. According to the HR Manager, the succession planning programmes are existent within the company, however, the implementation is not effective and they are not properly communicated. This is evident from several respondents who alluded that they are not aware that there are succession plans within the company. On the other hand, several respondents 
Sindisiwe Bonisile Mhlongo \& Martha Harunavamwe "Exploring Management's Perceptions of Succession Planning and its Impact on Staff Retention at an Agricultural Company"

do not have confident in the current succession planning programmes because they think it is biased and only favour a particular race. One respondent mentioned that "we are a German-based company; senior managers are in these positions purely because of race".

\section{Conclusions to Theme 3 and Objective 3}

It is evident from the analysis of data that there are retention challenges at the company. The main challenges pertain to remuneration and the company's geographical location. In terms of using the current succession planning programmes as a means of retaining employees, it can be concluded that the company is not doing so well. Even though there are successions planning programmes in place within the company, they are not effectively implemented and they are not communicated properly within the company. It appears that managers would be motivated to stay longer if they are part of the succession planning programme.

\section{Key Findings}

The purpose of this section was to highlight the key findings of this study which are presented as follows:

- There is a general understanding of what succession planning is.

- Managers perceive that the company is not doing enough to effectively implement succession planning programmes.

- There are potential internal candidates who can be trained to succeed current managers in the future.

- The current management training and development programmes are not implemented in a transparent and effective manner.

- Several factors affect the successful implementation of succession planning and these include but not limited to lack of top management commitment to succession planning, poor communication, lack of employee motivation, time and budgetary constraints.

- Retention of managers is a challenge at the company due to the geographical location of the company, remuneration issues, size of the company (which affects employee-growth prospects), and job satisfaction.

\section{CONCLUSION AND RECOMMENDATIONS}

\section{Implications of the study}

Based on the findings of this study, the following implications within the sector are made which relate to managements' perceptions regarding succession planning practices and their impact on staff retention:

- It is revealed from the investigated company that internally there are candidates that can succeed the current managers in the future. However, there are no proper or formal systems in place that are utilised to identify this talent pool and prepare it for succession. This study suggests, therefore, the development and implementation of systems that endeavour to discover talent internally. The Human Resources and Training and Development can team up to develop such systems.

- This study found that there is lack of top managements' emphasis around the implementation of succession planning programmes. Literature indicated that top management is key in ascertaining successful implementation of succession planning practices. Therefore, this study suggests that top management should be proactive and be seen as agents that drive the succession planning practices.

- Moreover, this study contributes to the identification of staff retention challenges peculiar to sugar manufacturing companies such as quality of life due to the geographic location of such companies. The contribution of this research is to add to the existing theories and concepts in succession planning practices in the sugar manufacturing sector. 
Sindisiwe Bonisile Mhlongo \& Martha Harunavamwe "Exploring Management's Perceptions of Succession Planning and its Impact on Staff Retention at an Agricultural Company"

\section{Limitations of this Study}

The study identified the following limitations:

- This qualitative type of research is subject to criticism because of limitations such as researcherrelated problems and fundamental design limitations. The study used in-depth interviews as the primary method of data collection and this is also subject to the same criticisms. During the coding process, interpretations and judgements by the researcher were required to categorise the interview data. Subjectivity was, therefore, unavoidable, which could lead to possible bias in the results. To reduce the level of this subjectivity, efforts were undertaken to ensure consistency while conducting interviews, and the analytical procedures of this study.

- Apart from bias relating to the researcher, informants are likely to contribute bias into the results. The accuracy and truthfulness of their opinions, comments, or perceptions collected during the interviews can never be fully tested. The picture emerged from the interview data is only a snapshot in time, and it does not necessarily reflect accurate accounts of particular realities. Although attempts were made to overcome this limitation by asking open-ended questions on key managers with different management roles at the company, it is unlikely to overcome the limitation completely. However, the inherent subjectivity and participant-related bias must be weighed against the richness of data captured and collected in the in-depth interviews. For this research, this method of primary data collection was deemed appropriate for the research topic, and it is believed that the benefits outweighed the possible bias.

- This study was also limited to one sugar manufacturing company within the province of KwaZuluNatal and only 15 individuals participated in this study. Generalisation should be exercised with care in terms of the findings being applicable to all sugar manufacturing companies in South Africa. It may add value to use multiple case studies with a larger sample size in order to increase rigour of the analysis and to compliment this study.

\section{Recommendations}

It is evident from the findings that the company has developed succession planning policies and programmes. It was discovered that the application of such programmes and practices comes with limiting factors that impede the successful implementation of succession planning practices and as such, these affect staff retention.

Top management participation: It is recommended that top management be seen as drivers of succession planning by actively providing platforms that encourage these practices. The study, in line with literature, found that top management are the custodians of succession planning programmes and they are influential. Top managements' participation will facilitate in providing leadership and direction regarding the implementation of succession planning. Therefore, a laissez-faire approach from them impedes the successful implementation of succession planning.

Employee participation: This study found that employees are motivated to stay within the company if they would be involved more in succession planning programmes. Therefore, as a retention strategy, this study recommends that employees be engaged in succession planning programmes. The succession planning programmes need to be communicated properly with the employees to make them aware of the future plans that the company has for them.

Effective communication channels: The company is encouraged to improve its communication of information across all divisions and all its employees. This can be achieved by an effective use of staff-portal, emails, notice boards, newsletters and meetings. These channelled are envisaged to improve the dissemination of critical information in as far as succession planning is concerned.

Internal talent search strategy: It is recommended that the company develop an internal talent search system. This will help channel the succession planning resources efficiently. This can be achieved by an effective use performance appraisal systems and assessments that would be designed for the identification of suitable candidates that can be developed for future management positions.

Flexible working conditions: The study found that time to train or to get trained in staff development programmes is a challenge. Flexible work-loads and working conditions are thus encouraged. This means that training managers should be afforded time to train those staff members who are undergoing training and development programmes. 
Sindisiwe Bonisile Mhlongo \& Martha Harunavamwe "Exploring Management's Perceptions of Succession Planning and its Impact on Staff Retention at an Agricultural Company"

Investment in succession planning programmes: Despite the fact that there are existing succession planning programmes, it was discovered that one of the reasons why they are not properly implemented was limitations in finances. The global economic situation might be a contributing factor towards limited funding in succession planning practices, however, to show commitment the company needs to be seen to be investing a bit more programmes that advance the application of succession planning programmes.

Improvement of staff recreational programmes: The major cause of staff retention problem at the company is its geographic location. Employees coming from the cities find it hard to cope with the culture and the environment under which they work. As a trade-off, this study recommends the improvement of recreational activities that should be intended to improve the quality of life of the company's employees and their families. This can be achieved by partnering with the employees in developing recreational programmes that will best suit them. Thus, the ideas should come from the employees rather than top management.

\section{Recommendations for Future Research}

This study recommends the following for future research:

- A longitudinal case study approach can be used to identify and evaluate the implementation of succession planning within the company. This type of study would provide a much richer and more detailed evaluation of the implementation of succession planning practices by the sugar manufacturing sector. This approach can assist in determining the extent at which these practices are used and how effective are they. Such a study can utilise multiple data collection methods, including interviews, observations, documents and, questionnaires, where appropriate. This type of study would provide a richer and more detailed explanation of the formation and implementation processes of succession planning programmes.

- This study explored management's perceptions regarding succession planning and its impact succession has on retention, using a company that is based in a rural village in Dalton, KwaZuluNatal. A similar study could be undertaken in other sugar manufacturing companies located in other parts of the province and it may incorporate other provinces as well. Such a study may provide further insight into the differences and similarities amongst sugar manufacturing companies' succession planning practices and their impact on staff retention in various locations within KwaZulu-Natal and in various provinces within the country.

- It may be critical that multiple case studies be conducted to evaluate the implementation of succession planning practices in the sugar manufacturing sector and the impact such practices have on staff retention in order to complement this study and to increase rigour of the analysis. This may mean that other provinces be taken into consideration as well.

- This study suggested several recommendations for the company with the aim of encouraging a successful implementation of succession planning practices. Future research is encouraged to critically evaluate the applicability and the effectiveness of these recommendations and suggest any possible improvements.

- This study used a qualitative approach. A quantitative method is recommended to test the relationship between various variables that affect the implementation of succession planning practices in the sugar manufacturing sector.

\section{Conclusion}

The study has contributed results and a research approach that could stimulate further research on the important issues that affect succession planning practices within the sugar manufacturing sector. The literature review and the empirical study revealed the management's perceptions on the implementation of succession planning practices at the company. The findings from the study helped in meeting all the objectives set for this study. Therefore, it can be concluded that despite the existence of succession planning policies and training and development programmes at the investigated company, there is still lack of effective implementation of such practices within the company. Contributing to the lack of successful implementation of these programmes are several factors which the study found to be limiting factors. As such, staff retention continues to be a challenge at the company. 
Sindisiwe Bonisile Mhlongo \& Martha Harunavamwe "Exploring Management's Perceptions of Succession Planning and its Impact on Staff Retention at an Agricultural Company"

\section{REFERENCES}

[1] Eshiteti, N.E., Okaka O., Maragia, S.N., Odera, O. and Akerele, E.K. (2013). Effects of Succession Planning Programs on Staff Retention. Mediterranean Journal of Social Science, 4(6), 157-162, July.

[2] Mehrabani, S.E and Mohamad, N.A. (2011). Identifying the Important Factors Influencing the Implementation of Succession Planning. International Conference on Information and Finance, 21(0), 37-41.

[3] Garg, A.K. and Van Weele, E. (2012). Succession Planning and Its Impact on the Performance of Small Micro Medium Enterprises within the Manufacturing Sector in Johannesburg. International Journal of Business and Management, 7(9), 96-107, May.

[4] Human Resource Development Council, HRDC. (2012). A Study on Labour Shortage in the Manufacturing Sector in Mauritius [online] Available from: http://www.hrdc.mu/index.php/downloads/category/7-labour-shortage-

surveys?download=25:labour-shortage-report-manufacturing-eoe-sector-october-2012[Accessed 8 May 2016].

[5] Gulzar, S.S. and Durrani, A. (2014). Impact of Succession Planning on Employee Engagement in Telecommunication Sector in Rawalpindi, Pakistan. European Journal of Business and Management, 6(33), 274-281.

[6] Durst, S. and Wilhelm, S. (2012). Knowledge management and succession planning in SMEs. Journal of Knowledge Management, 16(4), 637-649.

[7] Hall-Ellis, S.D. (2015). Succession planning and staff development - a winning combination. The Bottom Line: Managing library finances, 28(3), 95 - 98.

[8] Mathur, A. (2011). Succession Planning: A Planning that turns out into a legacy. International Journal of Management and Technology, 19(2), 50-59, July - December.

[9] Adewale, O.O, Abolaji, A.J. and Kolade, O.J. (2011). Succession Planning and Organizational Survival: Empirical Study on Nigerian Private Tertiary Institutions. Serbian Journal of Management, 6(2), 231 - 246, September.

[10] Stadler, K. (2011). Talent Review: The Key to Effective Succession Management. Business Strategy Series, 12(5), 264-271.

[11] Neo, R.A., Hollenbeck, J.R., Gerhart, B. and Wright, P.M. (2012). Human Resource Management: Gaining a Competitive Advantage .Eighth Edition. New York: Irwin McGrawHill.

[12] Tunje, G.S. (2014). Relationship between succession planning practices and employee retention in large media houses in Kenya. Unpublished MBA Dissertation. Kenya: University of Nairobi.

[13] Schroeder, R.G., Goldstein, S.M. and Rungtusanatham, M.J. (2013). Operations Management in the Supply Chain: Decision and Cases. Sixth Edition. United States of America: McGraw-Hill.

[14] Chitsaz-Isfahani, A. and Boustani, H. (2014). Effects of Talent Management on Employees Retention: The Mediate Effect of Organisational Trust. International Journal of Academic Research in Economic and Management Sciences, 3 (5), 114-128, September.

[15] Das, D.L. and Baruah, M. (2013). Employee Retention: A Review of Literature. IOSR Journal of Business and Management (IOSR-JBM), 14(2), 08-16, Nov-Dec.

[16] Waruiru, W.E. and Kagiri, A.W. (2015). Effects of Succession Planning Strategy on the Performance of International Non-Governmental Organizations in Kenya. International Journal of Science and Research, 4(5), 3147-3155, May.

[17] Mutunga, F. and Gachunga, H. (2013). Factors affecting Succession Planning in Small and Medium Enterprises in Kenya. International Journal of Academic Research in Business and Social Science, 3(8), 285-300, August.

[18] McCarthy, D. (2013). Ten Succession Planning Best Practices [online] Available from: https://www.ivyexec.com/executive-insights/2013/10-succession-planning-best-practices/ [Date of access: 8 Jul 2016].

[19] Blazevic, G. (2013). Mentoring for sugar industry succession and growth. Sugar Research Australia Ltd [online]. Available from: http://elibrary.sugarresearch.com.au/ [Date of access: 23 March 2016]. 
Sindisiwe Bonisile Mhlongo \& Martha Harunavamwe "Exploring Management's Perceptions of Succession Planning and its Impact on Staff Retention at an Agricultural Company"

[20] Govender, I. (2010). Succession Planning as a tool to minimise staff turnover rate: A case study of Nedbank Homeloans' KZN operations. MBA Dissertation. KwaZulu-Natal: University of KwaZulu-Natal.

[21] Kowalewski, S.J., Moretti, L. and McGee, D. (2011). Succession Planning: Evidence from "Best Companies in New York". International Journal of Management and Marketing Research, 4(2), 99-108.

[22] Coward, L.A. (2012). A Quantitative Study: Administrative Leaders' Perceptions of Succession Planning and Management Practices Within Community Colleges. Doctor of Philosophy Dissertation. Austin: University of Texas.

[23] Koranteng , F.A. (2014). Assessing Talent Management As A Tool For Employee Retention- A Case Study Of Procredit Savings And Loans Limited Kumasi. MBA Dissertation. Kwame Nkrumah University of Science and Technology.

[24] Terera, S.R. and Ngirande, H. (2014). The Impact of Rewards on Job Satisfaction and Employee Retention. Mediterranean Journal of Social Sciences, 5 (1), 481 - 487.

[25] Selesho, J.M. and Naile, I. (2014). Academic Staff Retention as a Human Resource Factor: University Perspective. International Business \& Economics Research Journal, 13 (2), 295 304.

[26] George, C. (2015). Retaining professional workers: what makes them stay? Employee Relations, $37(1), 102-121$.

[27] Zikmund, W.G., Babin, B.J., Carr, J.C. and Griffin, M. (2013). Business Research Methods.Ninth Edition. Canada: South-Western Cengage Learning.

[28] Barbour, R. (2014). Introducing Qualitative Research: A Student's Guide.Second Edition. London: SAGE Publications.

[29] Flick, U. (2014). An Introduction to Qualitative Research. Fifth edition. London: SAGE Publications Ltd.

[30] Collis, J. and Hussey, R. (2003). Business Research: a practical guide for undergraduate and postgraduate students. Second edition. Hampshire: Palgrave Macmillan.

[31] Creswell, J.W. (2015). A concise introduction to Mixed Methods Research. California: SAGE Publications, Inc.

[32] Baxter, P. and Jack, S. (2008). Qualitative case study methodology: study design and implementation for novice researchers. The Qualitative Report, 13(4): $544-559$.

[33] Burritt, R.L. and Saka, C. (2006). Environmental management accounting applications and ecoefficiency: case studies from Japan. Journal of Cleaner Production, 14 (14): 1262 - 1275.

[34] Yin, R.K. (2012). Applications of Case Study Research. Third Edition. California: SAGE Publications, Inc.

[35] Saunders, M., Lewis, P. and Thornhill, A. (2012). Research Methods for Business Students. Sixth Edition. Harlow, England: Financial Times, Prentice Hall.

[36] Chang, H. (2007). Environmental management accounting within universities: current state and future potential. Doctor of Philosophy Thesis, RMIT University.

[37] Sekaran, U. and Bougie, R. (2013). Research Methods for Business: A Skill-Building Approach. Sixth Edition. West Sussex: John Wiley and Sons Ltd.

[38] Zikmund, W.G., Babin, B.J., Carr, J.C. and Griffin, M. (2013). Business Research Methods.Ninth Edition. Canada: South-Western Cengage Learning.

[39] Lapan, S.D., Quaetaroli, M.T. and Riemer, F.J. (eds). (2012). Qualitative Research: An introduction to methods and designs. San Francisco: John Wiley and Sons.

[40] Tracey, S. (2013). Qualitative Research Methods: Collecting evidence, crafting analysis, communicating impact. West Sussex: Wiley-Blackwell.

[41] Masanet-Llodra, M.J. (2006). Environmental Management Accounting: A case study research on innovative strategy. Journal of Business Ethics, 68 (4), 393 - 408. 